\title{
A FAMÍLIA PERETTI GURTENSTEN: INDICATIVOS PARA UMA PESQUISA SOBRE EMPRESARIADO E POLÍTICA PARANAENSE
}

\author{
Marcus Roberto de Oliveira ${ }^{1}$
}

- Enviado em 28/05/2016

- Aprovado em 30/05/2016

\section{RESUMO}

O presente texto busca chamar atenção para a presença de grandes empresas na política paranaense. Esse pouco estudado comparecimento expõe, preliminarmente, um relacionamento imediato entre campo empresarial e campo político. Assim, tomando como ponto de partida essa convivência, a atuação da família Peretti Gurtensten (tradicional no ramo da construção civil) no cenário político do Paraná figura enquanto um exemplo muito expressivo. Conforme as informações preliminarmente arroladas, a família Peretti Gurtensten pode ser compreendida como um conjunto de agentes sociais que participa ativamente nos campos empresarial e político do Paraná. A referida posição revela a significativa posse, por parte dos mesmos, de capitais sociais. A partir dessa realidade, a realização de estudos acadêmicos sobre essa família aparece de maneira conexa e interessante.

Palavras-chave: Campo social. Capital social. Família Peretti Gurtensten. Política paranaense.

\section{INTRODUÇÃO}

Na sociologia proposta por Pierre Bourdieu, o conceito de "campo social" formaliza a existência de microcosmos sociais que, dotados de lógica própria e relativa autonomia, apresentam

1 Doutorando em Sociologia pela Universidade Federal do Paraná (UFPR). Endereço eletrônico: mr_olivei@yahoo.com.br 
um constante e dinâmico cenário de lutas e conflitos, envolvendo a autoridade expressa em cargos de mando socialmente reconhecidos (relações de poder) e o acúmulo de capitais sociais fundamentais para seus respectivos funcionamentos (BOURDIEU, 1996). Nessa lógica, O capital social pode ser definido enquanto um recurso mobilizador. Nesse sentido, sua diversidade pode expressar um "conjunto de recursos atuais e potenciais que estão ligados à posse de uma rede durável de relações mais ou menos institucionalizadas” (MATOS, 2009, p. 35).

Os processos conflitivos que caracterizam os campos sociais ocorrem num consolidado contexto de distribuição desigual dos capitais sociais característicos de cada campo ou, em outras palavras, de diferenciação social. Assim, os campos sociais são espaços estruturados e neles, conforme suas respectivas correlações de forças e normas constitutivas, predominantes e jugulados pleiteiam lucros específicos (BOURDIEU, 1996).

Enquanto ambientes estruturados e definidos por lutas e confrontos acerca da posse de capitais sociais peculiares, bem como por uma contínua sucessão de habitus ${ }^{2}$ referentes aos agentes sociais envolvidos, os campos sociais, reafirmando suas relativas autonomias e lógicas próprias, apresentam uma significativa variedade. Nesse ponto é possível identificar os campos da moda, religioso, político, científico, artístico, empresarial, etc.

Diante de tal multiplicidade é possível identificar (e destacar), a partir do momento em que problematizações de pesquisa são delimitadas e fundamentadas, os diversos capitais sociais abrangidos no funcionamento de um determinado campo e as formas de relacionamento que esse tem com os demais campos sociais existentes. Nesse raciocínio, o presente texto busca chamar atenção para a presença de grandes empresas na política paranaense. Esse pouco estudado comparecimento expõe, preliminarmente, um relacionamento imediato entre campo empresarial e campo político. E considerando a complexidade que permeia os processos políticos brasileiros, um número significativo de agentes compartilham espaços nesses dois campos. Assim, tomando como ponto de partida essa convivência, a atuação da família Peretti Gurtensten (tradicional no ramo da construção civil) no cenário político do Paraná figura enquanto um exemplo muito expressivo.

\footnotetext{
${ }^{2}$ Conforme Bourdieu, o habitus é definido enquanto um arrolamento de disposições para determinadas práticas prática; seriam produtos coletivos que orientam as ações dos agentes (BOURDIEU, 1996).
} 
A construtora Hugo Peretti Companhia Ltda foi constituída "em Curitiba no dia 18 de janeiro de 1945, por Hugo Peretti, Engenheiro Civil formado pela Universidade Federal do Paraná”. A empresa de Peretti ficou conhecida devido ao seu pioneirismo "em soluções tecnológicas" e segue marcando uma forte presença no "cenário da construção no Paraná". Entre as principais obras estão o "Victoria Villa Hotel e também o Hospital Erasto Gaertner". Na atualidade, os diretores Percy Peretti e Hugo Peretti Neto (respectivamente, filho e neto de Hugo Peretti) comandam a construtora ${ }^{3}$.

Nos pontos assinalados, os ofícios da construção civil conjugados à tradição familiar podem ser indicativos da existência (e operação) de capitais sociais, especificamente os tipos econômico, tecnológico e familiar. Assim, em termos metodológicos, o referido conjuminado abre espaço para uma produção antroponômica; a qual é definida enquanto

(...) a produção da energia humana, ao mesmo tempo em quantidade e qualidade, ao mesmo tempo como fonte pura ("bruta") (produção material - grifos nossos) e como modos específicos de concretização (produção cultural - grifos nossos): as energias "qualificadas" do artesão, do trabalhador profissional, da enfermeira, do artista, da mãe de família, e também do banqueiro, do político, do jornalista. É a produção dos próprios seres humanos, não enquanto seres biológicos, mas enquanto seres sociais (BERTAUX, 1979, p. 56).

A antroponomia está associada à produção de pessoas no âmbito social. Na constante interação que envolve as produções materiais, que podem ser compreendidas como as condições materiais vigentes numa vivência humana, e as produções culturais, definidas enquanto as "aptidões para fazer este ou aquele trabalho, a exercer essa ou aquela atividade" (Idem, p. 56).

Um procedimento antroponômico alude às participações da família, dos amigos, da escola, da igreja, da ocupação profissional e da própria pessoa. Nesse encaminhamento uma significativa quantidade de informações pode ser levantada sobre a trajetória da família Peretti Gurtensten. Em 2008, o "primeiro shopping center de Curitiba, que é o Mueller", comemorava seu $25^{\circ}$ aniversário

\footnotetext{
${ }^{3}$ Disponível em http://www.bonde.com.br/?id bonde=1-14-2-24-20090323; acesso em 18/05/2016.
} 
em 12 de setembro daquele ano, "em grande estilo, no Castelo do Batel ${ }^{4}$. O shopping pertencente aos empresários Salomão Soifer e Sabrina Peretti, cresceu muito nestas duas décadas e meia"5. Já em março de 2011, a "Construtora Hugo Peretti assinou, (...), um contrato com a empresa de consultoria e projetos de engenharia Intertechne", tendo como objetivo a construção de um grande empreendimento empresarial na cidade de Curitiba. Nessa empreitada também é possível notar a amplitude empresarial dessa família, pois a "Saga Participações, representada pelas sócias Maria Gabriela Peretti e Sabrina Peretti Gurtensten é também parceira na construção do empreendimento" ${ }^{6}$. A participação ativa da empresa no setor proporcionou ao grupo

(...) importantes premiações, entre elas o Troféu Incorporador do Ano 2012, concedido pela Associação dos Dirigentes de Empresas do Mercado Imobiliário do Paraná (ADEMI-PR), na categoria "Incorporadora do Ano". O prêmio é o mais importante da entidade e um dos mais expressivos do setor no estado. Em 2014, recebeu a certificação internacional LEED Leadearship in Energy and Environmental Design, na categoria GOLD, pelo empreendimento Centro Empresarial Antonio Peretti, construído com base no conceito "Green Building”, que prevê a racionalização de recursos e o uso de avançadas tecnologias para minimizar os impactos negativos da construção no meio ambiente. ${ }^{7}$

Tais informações surgem como indícios de uma bem sucedida combinação entre capitais econômicos, tecnológicos e familiares que abrange uma grande rede componente do campo empresarial. Assim, os procedimentos metodológicos antroponômicos figuram como instrumentos muito pertinentes.

Tamanho prestígio não poderia deixar de alcançar outro campo social específico: o campo político. Nessa questão merece menção Laís Peretti Gurtensten, curitibana, "nascida em 18/07/1943, casada com Milton Gurtensten, mãe de 3 filhas: Débora, Sabrina e Maria Gabriela”,

4 "O Castelo do Batel é uma relíquia arquitetônica que se impõe na mais nobre região de Curitiba. É um verdadeiro tesouro de uma época gloriosa, cenário de grandes festas e hóspedes ilustres" (Disponível em http://www.castelodobatel.com.br/?page id=5; acesso em 18/05/20016).

${ }^{5}$ Disponível em http://miriangasparin.com.br/2008/09/os-25-anos-do-shopping-mueller/; acesso em 18/05/2016.

${ }^{6}$ Disponível em http://bebelritzmann.blogspot.com.br/2011/04/hugo-peretti-constroi-o-primeiro-green.html; acesso em $18 / 05 / 2016$.

${ }^{7}$ Disponível em http://jornalwebdigital.blogspot.com.br/2015/12/hugo-peretti-apresenta-nova-diretora.html; acesso em $\underline{18 / 05 / 2016 .}$ 
formada em "Pedagogia pela Universidade Federal do Paraná e em Belas Artes pela Escola de Música e Belas Artes do Paraná", ocupou o cargo de "coordenadora da Casa da Gravura, no Solar do Barão, de 1982 a 1985", sendo "eleita vereadora em 15/11/1988" - pelo Partido do Movimento Democrático Brasileiro (PMDB) - "assumindo em 01/01/1989 com propostas voltadas basicamente para o social", vindo a falecer num acidente de carro em 13 de janeiro de $1991{ }^{8}$. Laís Peretti Gurtensten era vista enquanto

(...) uma pessoa dinâmica, combativa e de vanguarda. Valorizava a cultura e, como artista plástica, percebia estar o papel do artista inserido no contexto social no qual ele vive e que a arte, se posta em defesa de relações de trabalho justas, auxiliaria as forças sociais a criarem uma civilização de trabalho em contrapartida à civilização do capital.

Defendia a valorização da mulher e acreditava que as mulheres estavam preparadas e motivadas para compartilhar responsabilidades com os homens em todas as áreas. Reconhecia que o Brasil se modernizara em vários aspectos externos, mas que essas modernidades não vieram acompanhadas da noção equivalente de liberdade espiritual e mental que se adaptassem aos novos tempos. Dizia que uma certa colonização cultural provocava grandes danos nos valores éticos de nossa sociedade.

Considerava a revitalização do ensino público uma tarefa urgente e se rebelava com a falta de todo e qualquer estímulo para que os professores pudessem exercer sua missão com dignidade e competência. Sonhava com um Brasil livre do analfabetismo e da miséria. Lutava pela democratização das oportunidades de ascensão social da população marginalizada e por salários e sistema de saúde pública dignos. ${ }^{9}$

Em termos retóricos é possível presumir que Laís Peretti Gurtensten direcionava sua atuação pública às temáticas das artes, do feminismo e da inclusão social. Nessa jornada, a vereadora revela, além de sua condição enquanto agente social do campo político, uma participação sistemática, da mesma ordem, no campo artístico. Mas cabem as perguntas: E quanto ao campo empresarial? Sua obra política contemplava os negócios da família? Ao longo da coleta dos dados preliminares acerca de Laís Peretti Gurtensten, não foram encontradas informações características de iniciativas voltadas ao campo empresarial. Porém, um arrolamento aprofundado sobre esse assunto merece atenção, sobretudo por uma polêmica situação póstuma que envolve a relação de uma grande obra

\footnotetext{
${ }^{8}$ Disponível em http://www.educacao.curitiba.pr.gov.br/conteudo/historico/3873; acesso em 20/05/2016.

${ }^{9}$ Idem nota anterior.
} 
da família Peretti Gurtensten (o Centro Empresarial Laís Peretti, localizado no bairro Alto da Glória em Curitiba-PR) com a Companhia de Saneamento do Paraná (SANEPAR).

No ano de 2013, a diretoria SANEPAR formalizou um contrato de R 14 milhões no aluguel de salas comerciais para o funcionamento de suas repartições pelo período de 5 anos. O imóvel objeto do convênio é o Centro Empresarial Laís Peretti, de propriedade da empresa L. Peretti Empreendimentos Imobiliários Ltda. Conforme a ata do Conselho de Administração (CAd) da SANEPAR, sob o crivo do conselheiro Mauricio Jandoi Fanini Antonio, observa-se o

\begin{abstract}
Contrato de Locação de Imóvel destinado às instalações das Unidades que serão remanejadas da Sede Administrativa e de imóveis locados em Curitiba, firmado entre a Sanepar e a empresa L. PERETTI EMPREENDIMENTOS IMOBILIÁRIOS LTDA., referente à locação do imóvel situado à Av. João Gualberto, n! 1.259 , do Centro Empresarial Laís Peretti, bairro Alto da Glória, em Curitiba, composto pela sobreloja Salas 2 e 3 e por 18 Conjuntos Comerciais totalizando $3.631,00 \mathrm{~m} !^{2}$ e 42 vagas de garagem indeterminadas, de acordo com a matrícula n! 47.374 do Cartório do Registro de Imóveis da $2^{a}$ Circunscrição de Curitiba, no valor de $R \$ 232.384,00$ mensais, com vigência contratual de 01/11/2013 a 31/10/2018. Parecer Técnico-Jurídico n! ${ }^{\circ}$ 116/2013-US Ju/CLI, ratificado pela DJ em 11/07/2013. Processo de Contratação de Locação para Aprovação n! ${ }^{\circ}$ 056/2013-DA.
\end{abstract}

APROVADO" 10

No site do Tribunal Superior Eleitoral (TSE), a L. Peretti Empreendimentos Imobiliários Ltda., componente da Hugo Peretti \& Cia Ltda., aparece "na lista de doadores da campanha do governador Beto Richa (Partido da Social Democracia Brasileira - PSDB), de 2010”. Na ocasião, a “empresa doou R\$ 75 mil ao tucano". Assim, o contrato milionário lavrado pela SANEPAR foi "um negócio da China para a imobiliária L. Peretti" ${ }^{11}$. Na época, o deputado estadual Péricles de Mello (Partido dos Trabalhadores - PT), que ocupou o cargo de Diretor Administrativo na SANEPAR em 2005, comentou o assunto num pronunciamento na tribuna da Assembleia Legislativa do Paraná (ALEP):

10 Disponível em http://www.esmaelmorais.com.br/wp-content/uploads/2013/09/ata_sanepar.pdf; acesso em 20/05/2016.

11 Disponível em http://www.esmaelmorais.com.br/2013/09/sanepar-paga-r-14-milhoes-pelo-aluguel-de-salas-valordaria-para-comprar-o-imovel/; acesso em 20/05/2016. 
"Conforme informações que chegaram em minhas mãos, a empresa L. Peretti Empreendimentos Imobiliários, responsável pela locação do imóvel à Sanepar, é do mesmo grupo que participou do financiamento da campanha eleitoral de Richa. Além disso, cerca de 150 funcionários irão trabalhar no imóvel, mas, surpreendentemente, existem apenas 42 vagas de estacionamento. Esse tipo de negócio deve ser denunciado”, reforçou o deputado.

Péricles disse que em outros terrenos, de posse da Sanepar, haveria muito mais espaços para absorver um projeto como este. "É uma vergonha que uma empresa, estratégica para o Paraná, como é a Sanepar, se presta a fechar um contrato dessa natureza", argumentou. ${ }^{12}$

Portanto, conforme as informações preliminarmente arroladas, a família Peretti Gurtensten pode ser compreendida como um conjunto de agentes sociais que participa ativamente no campo empresarial do Paraná. A referida posição revela a significativa posse, por parte dos mesmos, de capitais sociais, especificamente, dos tipos econômico e tecnológico. A partir dessa realidade, também é possível notar que tais recursos mobilizadores conjugam-se com outros tipos de capital social: o capital familiar e o capital político. Tal arranjo garante, inclusive, a participação dos Peretti Gurtensten nos campos político e artístico. Assim, por meio de instrumentos antroponômicos, num contexto de ausência de análises relacionadas a tais agentes, a realização de estudos acadêmicos sobre essa família aparece de maneira conexa e interessante.

\section{REFERÊNCIAS}

BERTAUX, D. (1979). Destinos pessoais e estrutura de classe: para uma crítica da antroponomia política. Rio de Janeiro: Zahar.

BOURDIEU, P. (1996). Razões práticas: sobre a teoria da ação. Campinas: Papirus.

MATOS, H. (2009). Capital social e comunicação: interfaces e articulações. São Paulo: Summus.

http://bebelritzmann.blogspot.com.br/2011/04/hugo-peretti-constroi-o-primeiro-green.html; acesso em 18/05/2016.

http://miriangasparin.com.br/2008/09/os-25-anos-do-shopping-mueller/; acesso em 18/05/2016.

\footnotetext{
${ }^{12}$ Disponível em http://www.blogdodoc.com/r-14-mi-em-5-anos-pericles-denuncia-aluguel-pago-pela-sanepar/; acesso
} em 20/05/2016. 
http://www.blogdodoc.com/r-14-mi-em-5-anos-pericles-denuncia-aluguel-pago-pela-sanepar/; acesso em 20/05/2016.

http://www.bonde.com.br/?id_bonde=1-14-2-24-20090323; acesso em 18/05/2016.

http://www.castelodobatel.com.br/?page_id=5; acesso em 18/05/20016.

http://www.educacao.curitiba.pr.gov.br/conteudo/historico/3873; acesso em 20/05/2016.

http://www.esmaelmorais.com.br/2013/09/sanepar-paga-r-14-milhoes-pelo-aluguel-de-salas-valordaria-para-comprar-o-imovel/; acesso em 20/05/2016.

http://www.esmaelmorais.com.br/wp-content/uploads/2013/09/ata_sanepar.pdf; $\quad$ acesso em $20 / 05 / 2016$.

\title{
PERETTI GURTENSTEN FAMILY: INDICATIVE FOR RESEARCH AND ENTREPRENEURS PARANAENSE POLICY
}

\begin{abstract}
This paper seeks to draw attention to the presence of large companies in Paraná policy. This understudied attendance exposes preliminarily an immediate relationship between the business field and the political field. Thus, taking as a starting point, this cohabitation, the performance of Peretti Gurtensten family (traditional in the construction business) in the political scenario of Paraná figure as a very expressive example. As the preliminarily enrolled information, the Peretti Gurtensten family can be understood as a set of social agents that actively participates in the business and political fields of Parana. That position reveals the significant ownership, by the same, social capital. From this fact, conducting academic studies on this family appears related and interesting way.
\end{abstract}

Key-words: Social field. Social capital. Family Peretti Gurtensten. Paranaense policy. 